\title{
Cast immobilisation for the treatment of paediatric distal radius fracture: fibreglass versus polyolefin
}

\author{
Meng $\underline{Z h u}^{1}, \mathrm{MD}$, Elvin Salioc Lokino ${ }^{1}$, MD, Cheri Su Hui $\underline{\text { Chan }}^{1}$, BSc, Arlene Jeremie Gan ${ }^{1}$, MD, Ling Ling $\underline{\text { Ong }}^{1}$, RN, \\ Kevin Boon Leong Lim ${ }^{1}$, FRCSEd, FAMS
}

INTRODUCTION Stable distal radius fractures in children are frequently treated by immobilisation with a cast and heal readily without complications. This randomised clinical trial aimed to assess patient satisfaction and casting-related clinical outcomes when using polyolefin cast, a new cast material, compared to the conventional fibreglass cast.

METHODS A total of 80 patients (age range 7-16 years) with radiograph-confirmed stable distal radius fractures were recruited. They were randomised to either the fibreglass group or polyolefin group, with short arm cast immobilisation for 20-30 days. After cast removal, the incidence of skin rash, growth of hair and cast breakage was recorded along with the administration of patient satisfaction questionnaires. Mann-Whitney $U$ test or Fisher's exact test was applied to compare results.

RESULTS Overall, 34 patients from the fibreglass group and 31 patients from the polyolefin group were included in the final analysis. Significantly fewer patients from the polyolefin group reported itchiness during the casting period $(p=0.038)$. However, significantly more cast breakages were observed for the polyolefin group in the palmar bar region $(p=0.009)$. Patients from the polyolefin group were overall more satisfied (fibreglass group $=3.15 / 5$ vs. polyolefin group $=3.74 / 5 ; p=0.002$ ).

CONCLUSION Polyolefin cast reduces itchiness during casting and provides higher overall patient satisfaction during the treatment of stable distal radius fractures in children in tropical climates. However, patients should be counselled regarding potential cast breakage, which did not compromise safety, and the higher costs involved.

Keywords: cast, distal radius fracture, paediatric, patient satisfaction, polyolefin

\section{INTRODUCTION}

Forearm fractures are the most common fractures in children. ${ }^{(1)}$ Stable distal radius fracture is frequently treated by immobilisation with a cast and heals readily without complications. Traditionally, plaster of Paris has been used for its superior mouldability and conformability. However, synthetic materials, such as fibreglass, are becoming more popular and provide better patient satisfaction without compromising safety. ${ }^{(2,3)}$ With the new synthetic materials, skin irritation during casting is still a common complaint. A newly available cast material, with breathing holes that provide greater ventilation, could potentially reduce patients' suffering from itchiness, skin irritation and bad odour. Tubular hybrid mesh, with the addition of polyolefin, which is a chemical that has been used in diapers, has added extra skin protection from eruption or itching.

A recent study by Silva et $\mathrm{al}^{(4)}$ has shown that the new cast material resulted in faster recovery of physical function, while providing comparable stability, pain, itchiness, skin irritability and overall patient satisfaction. Their study focused on the influence of the use of waterproof cast materials on physical function but was limited by small sample size.

The objective of the present randomised clinical trial was to assess patient satisfaction and casting-related clinical outcomes when using polyolefin cast versus conventional fibreglass cast. We hypothesised that immobilisation with polyolefin cast could result in greater patient satisfaction among children with stable distal radius fractures when compared to fibreglass cast.

\section{METHODS}

All patients (age range 7-16 years) with radiography-confirmed forearm fractures seen at the orthopaedic outpatient clinic of a tertiary children's hospital in Singapore between March 2014 and March 2016 were eligible for recruitment. Patients who were diagnosed with stable distal radius fractures on radiography (buckle fracture or angulation $<15^{\circ}$ ), with or without associated distal ulnar fractures, were recruited. Exclusion criteria included existing skin conditions (e.g. eczema and psoriasis), allergy to cast materials, indications for reduction and fixation (e.g. unstable fracture, open fracture, neurovascular abnormalities or suspicion of a compartment syndrome) and previous surgeries to the affected forearm. A total of 80 patients were recruited in the study.

Patients were randomised, by choosing a sealed envelope with a preassigned random number, to either the fibreglass group (using Scotchcast Plus, 3M Health Care, Maplewood, Minnesota, U.S.) or polyolefin group (using HM Cast, Nam-gu, Daegu, Korea). These patients were immobilised with a short arm cast for the next 20-30 days. For both casts, cotton stockinet, as a protective sleeve adjacent to the skin, was applied over the area to be casted. For the fibreglass cast, another layer of Soffban Plus (BSN Medical, Hamburg, Germany) cotton padding was applied before the fibreglass cast was layered over the cotton padding to fit the fracture site. Routine cast care instructions were given to patients and parents/caregivers, with neither group allowed to wet the cast. 
Table I. Details of the patient satisfaction questionnaire.

\begin{tabular}{|c|c|c|c|c|c|}
\hline \multirow[t]{2}{*}{ Question } & \multicolumn{5}{|c|}{ Response } \\
\hline & 1 & 2 & 3 & 4 & 5 \\
\hline Smell & Distressing smell & Continual mild smell & Smell after hot day & Occasional smell & None \\
\hline Weight of cast & $\begin{array}{l}\text { Heavy cast, difficult } \\
\text { to use arm }\end{array}$ & $\begin{array}{l}\text { Moderately heavy. } \\
\text { Limited multiple } \\
\text { activities }\end{array}$ & $\begin{array}{l}\text { Mildly heavy. Limited } \\
\text { several activities }\end{array}$ & Fairly light & $\begin{array}{l}\text { Light cast. Did } \\
\text { not interfere with } \\
\text { activities }\end{array}$ \\
\hline Heat/sweat & $\begin{array}{l}\text { Very hot, wanted cast } \\
\text { removed }\end{array}$ & $\begin{array}{l}\text { Hot feeling worrying. } \\
\text { Complained a lot }\end{array}$ & $\begin{array}{l}\text { Often hot. Mild } \\
\text { distress }\end{array}$ & $\begin{array}{l}\text { Hot at times but } \\
\text { tolerable }\end{array}$ & Well tolerated \\
\hline Adaptation & $\begin{array}{l}\text { Uncomfortable } \\
\text { throughout }\end{array}$ & $\begin{array}{l}\text { Took up to a week to } \\
\text { become comfortable }\end{array}$ & $\begin{array}{l}\text { Fairly comfortable } \\
\text { after a few days }\end{array}$ & $\begin{array}{l}\text { Took } 1-2 \text { days to } \\
\text { become comfortable }\end{array}$ & $\begin{array}{l}\text { Very easy to get } \\
\text { used to }\end{array}$ \\
\hline $\begin{array}{l}\text { In the last three } \\
\text { weeks, has your cast } \\
\text { been comfortable? }\end{array}$ & Want cast removed & Irritating & $\begin{array}{l}\text { Fairly comfortable, } \\
\text { occasional irritation }\end{array}$ & Comfortable & Very comfortable \\
\hline Overall satisfaction & Intolerable & Bearable & $\begin{array}{l}\text { Good, overall } \\
\text { comfortable }\end{array}$ & Very comfortable & Excellent \\
\hline
\end{tabular}

All patients were reviewed after three weeks for cast removal. Upon cast removal, a nurse recorded the objective clinical findings with regard to any skin rash or growth of hair around the cast region, and any cast breakage. Each patient was asked to complete a patient satisfaction questionnaire regarding their experience with the cast, with or without the help of their parents. The questionnaire consisted of three items of 'yes/no' questions on skin itchiness, sleep disturbance and restriction of activities, and six items of five-point grading questions on various aspects regarding wearing the cast. Details of these questions are provided in Table I. The responses received from the recruited patients and their demographic data were collected and analysed.

Ethical approval was obtained from the centralised institutional review board and informed consent was obtained from the parent of each patient.

Statistical analyses were carried out using IBM SPSS Statistics 21.0 (IBM Corp, Armonk, NY, USA). Variables such as age, duration of casting and the grading questions from the patient satisfaction questionnaire were analysed using Mann-Whitney $U$ test. Variables such as gender, ethnicity and the 'yes/no' questions were analysed using Fisher's exact test. Correlations for the questionnaire questions were analysed using Pearson correlation coefficient. A p-value $<0.05$ was considered to be statistically significant.

\section{RESULTS}

The CONSORT flow diagram presents the progress of all patients through each stage of the study (Fig. 1). A total of 42 patients were randomised into the fibreglass group. However, three patients dropped out and five patients failed to complete the survey questionnaire. The polyolefin group had 38 patients following randomisation, but two patients dropped out and five patients failed to complete the survey questionnaire. Therefore, data were analysed for 34 patients from the fibreglass group and 31 patients from the polyolefin group.
There were no demographic differences between patients from the two groups and the duration of casting was similar (Table II). The clinical findings and responses of patients to the 'yes/no' questions are presented in Table III. Significantly fewer patients from the polyolefin group reported itchiness during the casting period ( $p=0.038)$. However, significantly more cast breakages were observed for the polyolefin group ( $p=0.009$ ). There were no statistical differences between the groups for the rest of the parameters investigated.

The mean patient satisfaction scores in the fibreglass and polyolefin groups showed no differences in patients' perceptions to smell, weight of the cast, heat/sweat during casting, adaptation to the cast, and comfort (Fig. 2). However, the overall satisfaction scores were significantly higher for the polyolefin group (fibreglass group $=3.15 / 5$ vs. polyolefin group $=3.74 / 5 ; p=0.002$ ). Positive correlations were observed between patient overall satisfaction and various aspects, such as itchiness, heat/sweat, adaptation to the cast and comfort.

\section{DISCUSSION}

This single-centre, randomised controlled study, which took into account both patient reported satisfaction and clinical parameters, strongly suggested that polyolefin cast provided greater patient satisfaction than the traditional fibreglass cast for the treatment of stable distal radius fractures in children, although more cast breakages were observed in the group.

Casting remains the main immobilisation method for stable distal radius fracture in children due to concerns over noncompliance with removable splints or other devices, although comparable outcomes have been demonstrated for these as well. $^{(5-7)}$ Fibreglass and other synthetic casting materials were more popular than plaster of Paris because they are lighter, less bulky, more durable and more water-resistant. ${ }^{(2)}$ Because none of the casting materials can be applied directly to the patient's skin, a padding or barrier, usually cotton (which is comfortable and porous), is applied before casting. Due to the layers of 


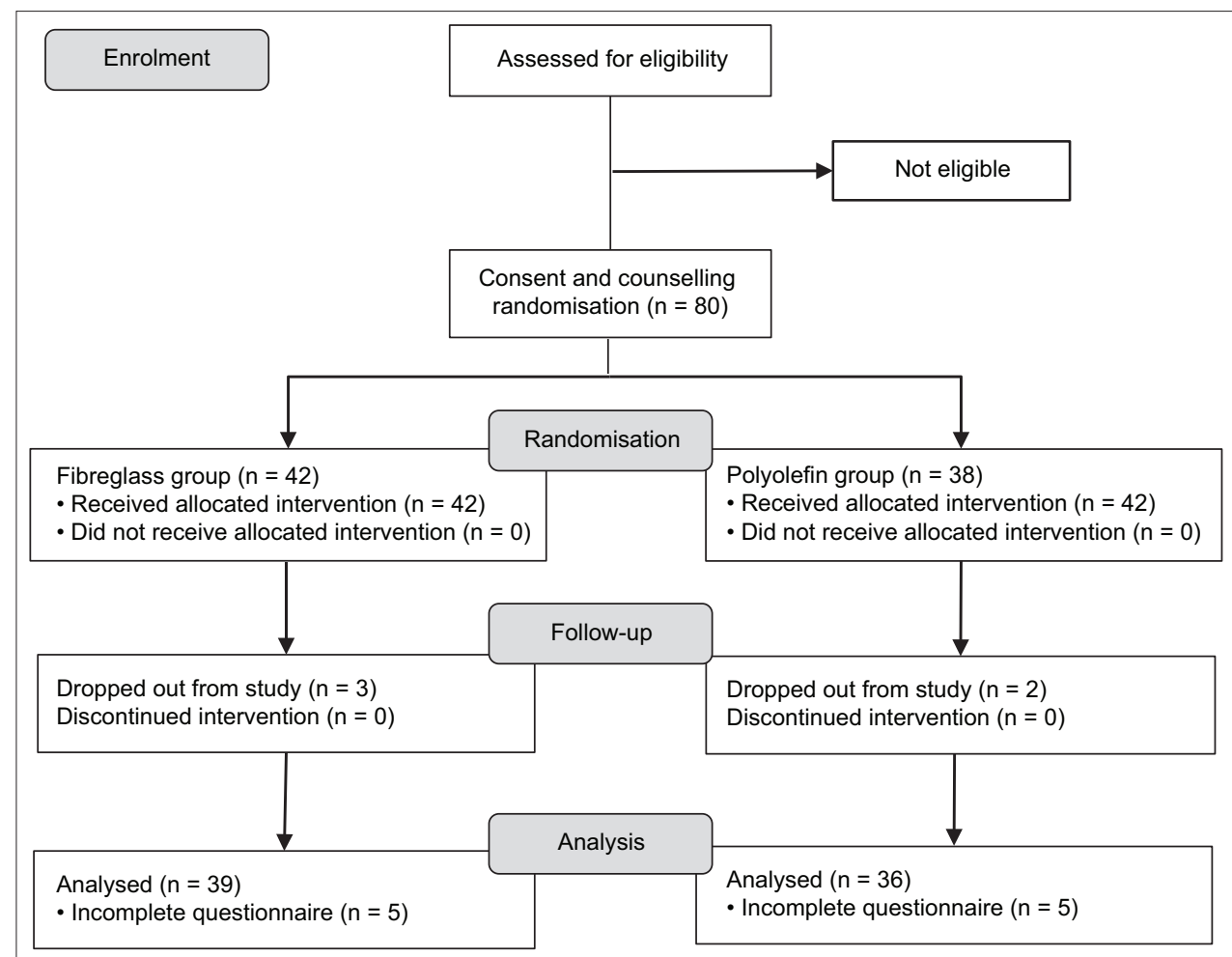

Fig. 1 CONSORT flow diagram shows the progress of all patients through each stage.

Table II. Patient demographics.

\begin{tabular}{|llll|}
\hline & \multicolumn{2}{c|}{ Mean \pm SD/no. } & p-value \\
\cline { 2 - 3 } & $\begin{array}{l}\text { Fibreglass cast } \\
(\mathbf{n}=\mathbf{3 4})\end{array}$ & $\begin{array}{l}\text { Polyolefin cast } \\
(\mathbf{n}=\mathbf{3 1})\end{array}$ & \\
\hline Age $(\mathbf{y r})$ & $11.6 \pm 2.53$ & $11.3 \pm 2.28$ & 0.504 \\
\hline Gender & & 26 & 0.375 \\
\hline Male & 25 & 5 & \\
\hline Female & 9 & & 0.435 \\
\hline Ethnicity & 16 & 15 & \\
\hline Chinese & 9 & 10 & \\
\hline Malay & 4 & 5 & 0.395 \\
\hline Indian & 5 & 1 & \\
\hline Other & $22.3 \pm 3.87$ & $23.2 \pm 4.04$ & \\
\hline $\begin{array}{l}\text { Duration of } \\
\text { casting (day) }\end{array}$ & & & \\
\hline
\end{tabular}

SD: standard deviation

padding and non-water-resistance, skin irritation is a common complaint leading to patient dissatisfaction, especially in the humid tropical regions. The addition of polyolefin to the cast materials to provide extra skin protection, together with good ventilation, can potentially provide a superior patient experience during casting and better patient satisfaction. Its unique pullover application technique and waterproof property enable patients to perform activities of daily living, which can further improve the quality of life during the casting period.

Silva et $\mathrm{al}^{(4)}$ postulated that earlier ability to perform activities, such as bathing, playing and swimming, could directly influence physical function. Therefore, a waterproof cast, by encouraging such activities, resulted in $10 \%$ higher performance on the
Table III. Partial responses to the questionnaire and objective findings after cast removal.

\begin{tabular}{|clll|}
\hline & \multicolumn{2}{c}{ No. of 'yes' responses } & \multirow{2}{*}{ p-value } \\
\cline { 2 - 3 } & $\begin{array}{l}\text { Fibreglass } \\
\text { cast }(\mathbf{n}=\mathbf{3 4})\end{array}$ & $\begin{array}{l}\text { Polyolefin } \\
\text { cast }(\mathbf{n}=\mathbf{3 1})\end{array}$ \\
\hline Questionnaire variable & & & \\
\hline Itch & 30 & 20 & $0.038^{*}$ \\
\hline Sleep disturbance & 3 & 1 & 0.615 \\
\hline Restriction of activities & 11 & 8 & 0.597 \\
\hline Objective finding & & & 0.430 \\
\hline Skin rash & 5 & 2 & 0.493 \\
\hline Hair growth & 2 & 0 & $0.009^{*}$ \\
\hline Cast breakage & 0 & 6 & \\
\hline
\end{tabular}

${ }^{*} \mathrm{p}<0.05$ is considered statistically significant.

Activities Scale for Kids as compared to the traditional fibreglass cast. However, comparable levels of pain, itchiness, skin irritability and overall patient satisfaction were reported for the two types of cast. The same waterproof cast was investigated in this study while also taking into account patient satisfaction, with focus on patient-reported itchiness and smell, and an objective assessment of skin condition after cast removal. To avoid patients' perceived benefits of waterproofing causing potential bias and confounding the results, both groups were not allowed to wet the cast and non-waterproof padding material was applied before casting. Although a crossover study was not conducted, no significant demographic differences were noted between the two groups. The benefits of waterproof cast and padding in improving hygiene and comfort without compromising fracture healing have been previously studied by others. ${ }^{(8-10)}$ 


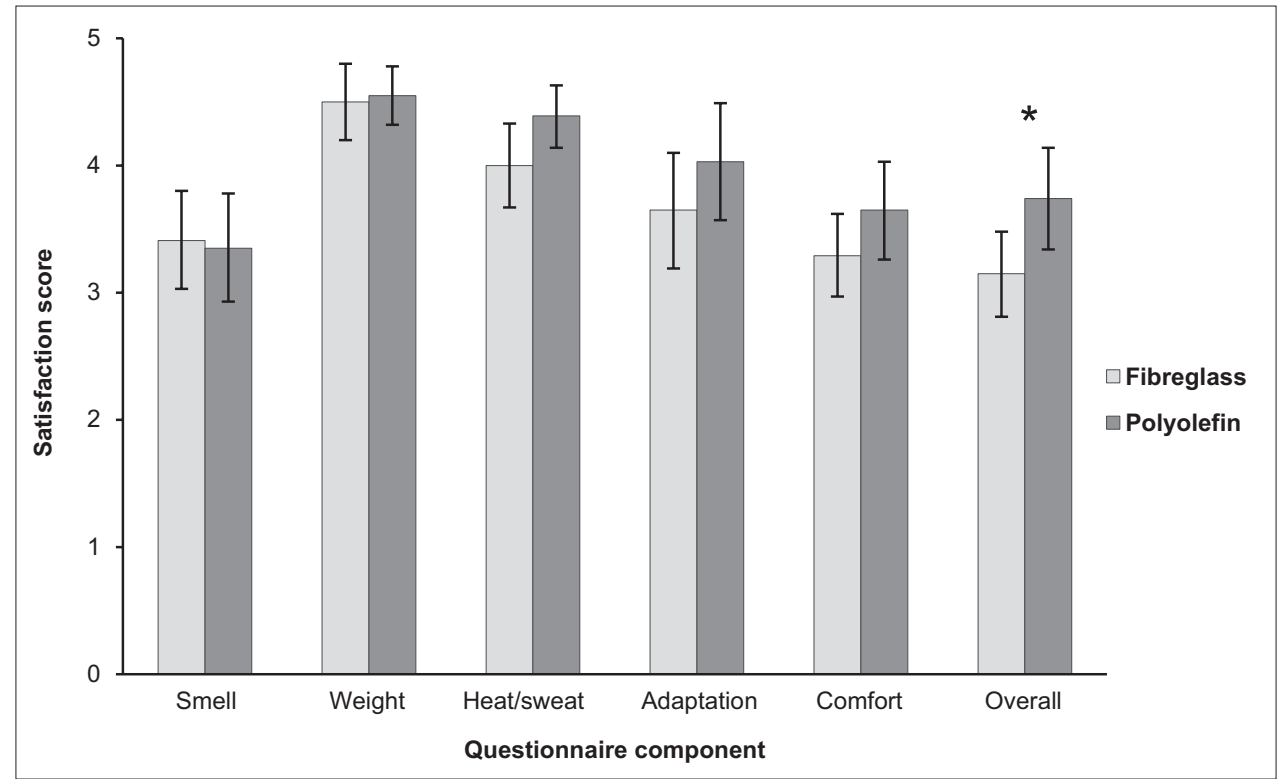

Fig. 2 Bar chart shows mean patient satisfaction score in the fibreglass and polyolefin groups. Error bars denote $95 \%$ confidence interval and asterisk denotes statistical significance at $\mathrm{p}<0.05$.

Itchiness is a significant contributor to overall patient satisfaction. Calamine lotion can be applied to reduce skin irritation, ${ }^{(11)}$ but this involves a one-time application that does not solve the root cause of the problem. The addition of polyolefin for skin protection and breathing holes for greater ventilation may contribute to less itchiness. Other aspects of patient satisfaction, such as heat/sweat during casting, adaptation to the cast, and comfort, although not significantly different between the two groups, were positively correlated to and played certain roles in the overall patient satisfaction.

One notable shortcoming of the polyolefin cast was its association with significantly more cast breakages. Post-removal analyses showed that all cast breakages happened in the palmar bar region. The area is subject to repeated stress during normal handgrip and provides minimal mechanical strength for stabilisation of fractures. Therefore, these cast breakages did not cause any loss of reduction or increase in complications. Cast breakages also did not translate into lower patient satisfaction and no demographic factors were associated with the cast breakages. Therefore, the polyolefin cast can still be safely applied for stable distal radius fractures.

There were a few limitations to our study. Only stable distal radius fractures were included in the study, limiting the generalisability of our results to all distal radius fractures in children, or fractures involving the proximal arms or lower limbs. Especially due to the higher rate of cast breakage for the polyolefin cast, further studies on the capabilities of maintaining reduction stability should be conducted. To the best of our knowledge, no valid and reliable scoring system exists for evaluating cast-related quality-of-life or patient satisfaction. Consequently, the questionnaire used in this study was adopted from a similar study comparing fibreglass cast against plaster of Paris. ${ }^{(3)}$ Nevertheless, objective clinical observations were also evaluated in this study to complement self-reported scoring. A compound score would be ideal for easy comparison but was unavailable. Cost analysis was not performed, as it was beyond the scope of the study. Fibreglass cast costs SGD 8 for each application, while each polyolefin cast costs about 2.5 times that amount (i.e. SGD 20). It is difficult to compare healthcare costs between the two groups due to the low complication rate of stable distal radius fractures. Moreover, the benefits of increased patient comfort and satisfaction at the cost of a more expensive cast should be weighed on a case-by-case basis when selecting cast material. Finally, the study was carried out in a tropical climate, and whether comparable results would be obtained in temperate climates is yet to be established.

In summary, polyolefin cast reduced itchiness during casting and provided higher overall patient satisfaction during the treatment of stable distal radius fractures in children in tropical climates. More cast breakages were observed among the polyolefin group patients when compared to the fibreglass group. It is recommended that polyolefin cast be used for stable distal forearm fractures, but patients should be counselled regarding potential cast breakages that do not impinge on safety or the reduction achieved, and the higher cost involved.

\section{REFERENCES}

1. Leung $\mathrm{KW}$, Mahadev A. The cost of sustaining playground related extremity fractures in Singapore. Injury 2011; 42:352-5.

2. Adkins LM. Cast changes: synthetic versus plaster. Pediatr Nurs 1997; 23:422, 425-7.

3. Inglis M, McClelland B, Sutherland LM, Cundy PJ. Synthetic versus plaster of Paris casts in the treatment of fractures of the forearm in children: a randomised trial of clinical outcomes and patient satisfaction. Bone Joint J 2013; 95-B:1285-9.

4. Silva M, Avoian T, Warnock RS, Sadlik G, Ebramzadeh E. It is not just comfort: waterproof casting increases physical functioning in children with minimally angulated distal radius fractures. J Pediatr Orthop B 2017; 26:417-23.

5. Oakley EA, Ooi KS, Barnett PL. A randomized controlled trial of 2 methods of immobilizing torus fractures of the distal forearm. Pediatr Emerg Care 2008; 24:65-70.

6. Boutis K, Willan A, Babyn P, Goeree R, Howard A. Cast versus splint in children with minimally angulated fractures of the distal radius: a randomized controlled trial. CMAJ 2010; 182:1507-12.

7. Hamilton TW, Hutchings L, Alsousou J, et al. The treatment of stable paediatric 
forearm fractures using a cast that may be removed at home: comparison with traditional management in a randomised controlled trial. Bone Joint J 2013; 95-B:1714-20.

8. Robert CE, Jiang IJ, Khoury JG. A prospective study on the effectiveness of cotton versus waterproof cast padding in maintaining the reduction of pediatric distal forearm fractures. J Pediatr Orthop 2011; 31:144-9.

9. Haley CA, Dejong ES, Ward JA, Kragh JF Jr. Waterproof versus cotton cast liners: a randomized, prospective comparison. Am J Orthop (Belle Mead NJ) 2006; 35:137-40

10. Derksen RJ, Commandeur JP, Deij R, Breederveld RS. Swim cast versus traditional cast in pediatric distal radius fractures: a prospective randomized controlled trial. J Child Orthop 2013; 7:117-21.

11. Mak MF, Li W, Mahadev A. Calamine lotion to reduce skin irritation in children with cast immobilisation. J Orthop Surg (Hong Kong) 2013; 21:221-5. 